\title{
ChemComm
}

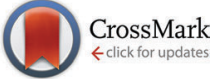

Cite this: Chem. Commun., 2015, 51, 7915

Received 15th January 2015, Accepted 1st April 2015

DOI: $10.1039 / c 5 c c 00415 b$

www.rsc.org/chemcomm

\section{A highly selective fluorescent sensor for glucosamine $\uparrow$}

\author{
Tam Minh Tran, Yuksel Alan and Timothy Edward Glass*
}

\begin{abstract}
A new fluorescent chemical sensor for glucosamine is reported. The sensor is based on a boronic acid-containing coumarin aldehyde and shows excellent selectivity for glucosamine by forming a boronic ester with the sugar diol as well as an iminium ion with the amine group of glucosamine. The sensor successfully discriminates glucosamine over other similar biomolecules in terms of both fluorescence intensity and binding affinity. This method provides a new concept for the design and synthesis of very selective turn-on optical sensors for selective detection of multi-functional biomolecules.
\end{abstract}

Glucosamine is one of the most popular non-prescription nutriceutical products on the market and has been used for years as an over the counter dietary supplement for the treatment of osteoarthritis, though its pharmacokinetics and pharmacodynamics are unclear. ${ }^{1-5}$ Many contradictory reports have been published about its efficiency at treating related diseases, such as rheumatoid arthritis, gastric ulcers and hepatitis. ${ }^{5-11}$ The normal cellular concentration of glucosamine is $1-2 \mu \mathrm{M}$, but can reach $10 \mu \mathrm{M}$ when taken orally. Recently, high concentrations of glucosamine and its derivatives have shown growth inhibitory effects against certain cancers. ${ }^{12-16}$ This important investigation could lead to potential development of new agents for cancer therapy. For these reasons, a fluorescent sensor that can selectively detect glucosamine in very complex media, such as the cell environment, would be an effective tool to support on-going research with glucosamine.

Significant effort has been made in developing fluorescent sensors for the discrimination of amine-containing biomolecules, including glucosamine. However, the high structural similarity of these biological amines, in addition to the complexity of cellular media, makes this endeavour difficult. To our knowledge, only a few sensors for glucosamine have been reported. ${ }^{17,18}$ Typically, sensors which bind ammonium ions use crown ethers as a recognition group. ${ }^{17}$ Although crown ethers can have good affinity toward

Department of Chemistry, University of Missouri, Columbia, MO 65211-7600, USA. E-mail: glasst@missouri.edu

$\dagger$ Electronic supplementary information (ESI) available: Synthesis, characterization of materials, and additional details. See DOI: 10.1039/c5cc00415b

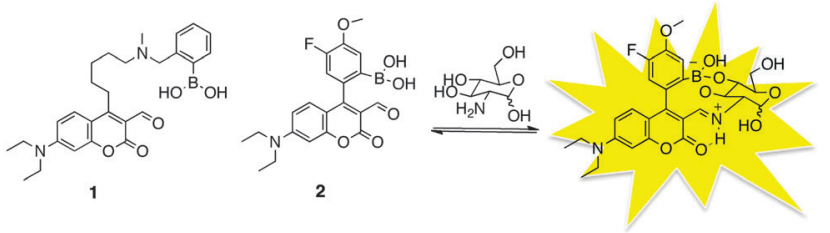

Scheme 1 A sensor for dopamine/norepinephrine (1); a sensor for glucosamine (2).

ammonium cations, they would likely not suffice for cellular use due to competition from the very high concentration of sodium ion. As a result, a turn-on fluorescent sensor that can bind to glucosamine with high selectivity remains challenging.

Our group has been developing a coumarin-aldehyde system for fluorescent sensing of amines. ${ }^{19-22}$ Some time ago, we introduced a fluorescent sensor (sensor 1, Scheme 1) for norepinephrine and dopamine by appending a phenyl boronic acid via a flexible linker to the coumarin aldehyde. ${ }^{20}$ Although, the sensor operated in a turn-off mode due to the quenching nature of catecholamines, the sensor showed good selectivity for norepinephrine and dopamine over many similar molecules including glucosamine. It was surprising that sensor 1 did not bind glucosamine well $\left(K_{\mathrm{a}}=5.0 \mathrm{M}^{-1}\right)$ since both dopamine and glucosamine have a diol and an amine in their structures. At the time, we speculated that sensor $\mathbf{1}$ had a cavity that was too large to accommodate glucosamine well, though admittedly, the cavity appeared to be quite flexible. In this report, we describe the design and properties of a new sensor that has a smaller binding cavity with a view toward binding glucosamine selectively.

To target glucosamine, sensor 2 was designed with a boronic acid group in the closest possible position to the aldehyde, creating a small pocket suited for the amino-sugar analyte, while also potentially excluding larger analytes. We have found that aryl-substituted coumarin-aldehydes perform very well as fluorescent sensors, ${ }^{22}$ so an ortho-phenylboronic acid was chosen for the diol-binding unit. A simple phenyl boronic acid has a $\mathrm{p} K_{\mathrm{a}}$ that is too high to operate properly at neutral $\mathrm{pH}$. Thus, most phenyl boronic acid-based receptors utilize an 

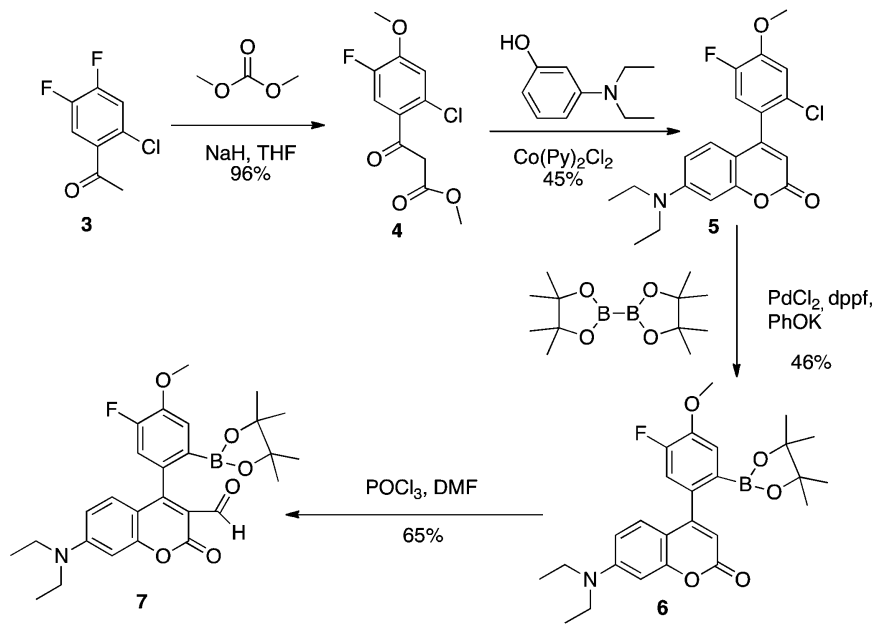

Scheme 2 Synthesis of sensor 2

aminomethyl substituent (e.g., sensor 1) to maintain the proper $\mathrm{p} K_{\mathrm{a}}$. For sensor 2 , a fluoro substituent was used to achieve the optimal $\mathrm{p} K_{\mathrm{a}}{ }^{23}$

The synthesis of the sensor 2 is outlined in Scheme 2 . Acetophenone derivative $\mathbf{3}$ was converted to ketoester 4 by Claisen condensation, ${ }^{24}$ which also resulted an $\mathrm{S}_{\mathrm{N}} \mathrm{Ar}$ substitution of the fluoro group para to the ketone with liberated methoxide. A Pechman reaction gave derivative $5{ }^{25}$ The chlorine substituent on intermediate $\mathbf{5}$ was converted to a boronic ester under palladium catalysis in moderate yield. $^{26,27}$ The sensor (as the boronate ester) was obtained via Vilsmeier-Haack formylation reaction under carefully controlled conditions due to the acid sensitivity of the boronate ester. $^{28}$ For these studies, compound 7 was used to prepare stock solutions of sensor $\mathbf{2}$ as the boronate ester hydrolysed in the dilute, aqueous media used for the titration experiments.

Sensor 2 was titrated with various primary amines to determine its selectivity profile (Table 1). The aldehyde group of sensor 2 can bind reversibly to the primary amines to form an iminium ion. ${ }^{19}$ The iminium ion enhances the internal charge transfer (ICT) of the coumarin, leading to a large red shift in the excitation spectra (Fig. 1a). By exciting the sensor at the red excitation wavelength, only the bound form is excited resulting in a large increase in fluorescence upon binding (expressed as $I_{\text {sat }} / I_{0}$ where $I_{\text {sat }}$ is the fluorescence of the sensor at saturation). When excited at $488 \mathrm{~nm}$ (a convenient wavelength) the sensor emission increases and shifts from $520 \mathrm{~nm}$ to $568 \mathrm{~nm}$ upon addition of glucosamine (Fig. 2b). Comparing results from dicarboxylate-containing guests such as glutamate and aspartate with the mono-carboxylate glycine and butylamine (no carboxylates) shows that the binding constants for such simple analytes are similar but the fluorescent response is stronger for analytes with more carboxylate groups. This effect stems from the fact that the carboxylates raise the $\mathrm{p} K_{\mathrm{a}}$ of the formed imine, producing more iminium ion, which is key to the sensor response. ${ }^{19}$ Secondary amines produce no response from the sensor.

Interestingly, not only did sensor 2 exhibit a very strong turnon fluorescence for glucosamine compared all other primary amines, but also an excellent binding constant $\left(K_{\mathrm{a}}=4100 \mathrm{M}^{-1}\right)$.
Table 1 Spectroscopic parameters for the interaction of sensor 2 with various analytes

\begin{tabular}{|c|c|c|c|c|c|}
\hline Guest & & $\lambda_{\mathrm{ab}}(\mathrm{nm})$ & $\lambda_{\mathrm{em}}(\mathrm{nm})$ & $K_{\mathrm{a}}^{a}\left(\mathrm{M}^{-1}\right)$ & $I_{\text {sat }} / I_{0}{ }^{b}$ \\
\hline D-Glucosamine & & 485 & 568 & 4100 & 32 \\
\hline Norepinephrine & & 487 & NA & $25^{c}$ & 0 \\
\hline D-Glucose & & 452 & NA & 35 & 0 \\
\hline L-Glutamic acid & $\mathrm{H}_{2} \mathrm{~N} \stackrel{\mathrm{CO}}{\stackrel{C}{(C)}}$ & 492 & 572 & 105 & 41 \\
\hline L-Aspartic acid & $\mathrm{H}_{2} \mathrm{~N}$ & 492 & 575 & 107 & 41 \\
\hline Glycine & $\mathrm{H}_{2} \mathrm{~N} \smile \mathrm{CO}_{2} \mathrm{H}$ & 484 & 565 & 93 & 22 \\
\hline$N$-Butylamine & & 455 & 550 & 73 & 13 \\
\hline Diethylamine & $\mathrm{H}$ & - & - & - & - \\
\hline
\end{tabular}

${ }^{a} K_{\mathrm{a}}$ measured by fluorescence spectroscopy, errors are $\pm 5 \%$ based on triplicate titration; titrations performed with sensor $2\left(10^{-5} \mathrm{M}\right.$ in $120 \mathrm{mM} \mathrm{NaCl}, 25 \mathrm{mM}$ HEPES, $\mathrm{pH}=7.4) .{ }^{b} I_{\text {sat }}$ : fluorescence intensity at saturation from a fit to the binding isotherm; $\lambda_{\mathrm{ex}}=488 \mathrm{~nm}$. ${ }^{c}$ Determined by absorption changes at $488 \mathrm{~nm}$.

This binding constant is nearly two orders of magnitude higher than that of the simple amino acids. The strong binding indicates glucosamine interacts with both the boronic acid and the aldehyde in a cooperative fashion (Scheme 1). ${ }^{29-33}$ It should be noted that boronic acids are well known to interact with the furanose form of glucose, ${ }^{34}$ and indeed, it may be possible that glucosamine adopts this form in solution as well. However, the formation of glucofuranose-boronic acid complexes is driven by the stability of the boronate ester of the 1,2 diol of the glucofuranose, which is not possible for glucosamine.

It appears from the titration data that norepinephrine, which also possesses both a primary amine and a diol, elicited a poor response from sensor 2 , both in terms of binding constant and fluorescence response (Table 1). Apparently, the small cavity between the boronic acid and the aldehyde in the sensor 2 is not suitable for the extended catechol system in norepinephrine. The observed absorption changes indicate that the iminium ion is formed, however cooperative binding of the catechol was not observed. Furthermore, the electron rich catechol engages in PET quenching with the electron poor coumarin giving an overall decrease in emission. This result stands in contrast to the high binding constant $\left(K_{\mathrm{a}}=6500 \mathrm{M}^{-1}\right)$ achieved with norepinephrine and sensor $1 .^{20}$ Thus, the cavity size of sensor 2 provides excellent discrimination between glucosamine and chatecholamines. In addition, glucose itself gives only a small change upon binding sensor 2 since it lacks an amine groups, and the binding constant is quite low, as expected.

To demonstrate the selectivity of sensor 2 , the sensor was mixed with equal concentration of analytes in buffer (Fig. 2a). A concentration of $1 \mathrm{mM}$ which is similar to therapeutic concentration was selected. ${ }^{35}$ Sensor 2 gave a much stronger fluorescence 

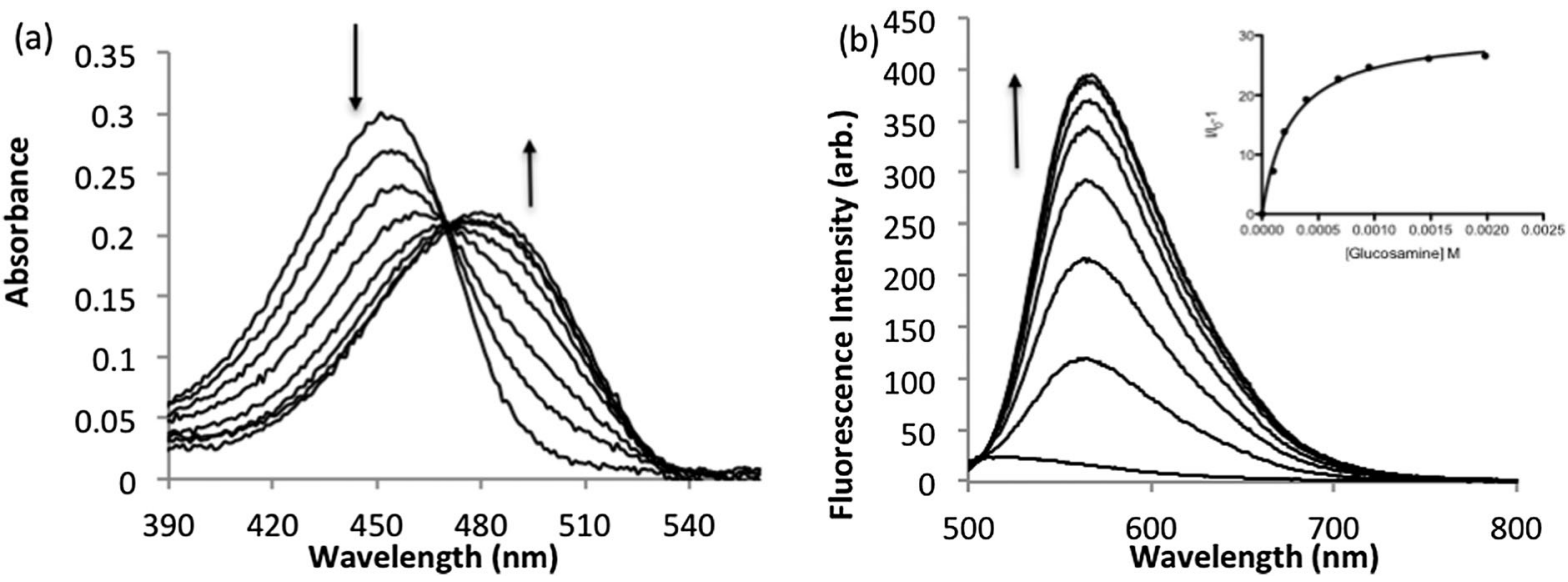

Fig. 1 (a) UV-vis absorption titration of sensor 2 with glucosamine ([2] $=10^{-5} \mathrm{M}$ in $120 \mathrm{mM} \mathrm{NaCl}, 25 \mathrm{mM} \mathrm{HEPES}$, pH = 7.4). (b) Fluorescence titration of sensor 2 with glucosamine $\left(\lambda_{\mathrm{ex}}=488 \mathrm{~nm}\right)$. Inset is a fit of the fluorescence data to a one-site binding isotherm.

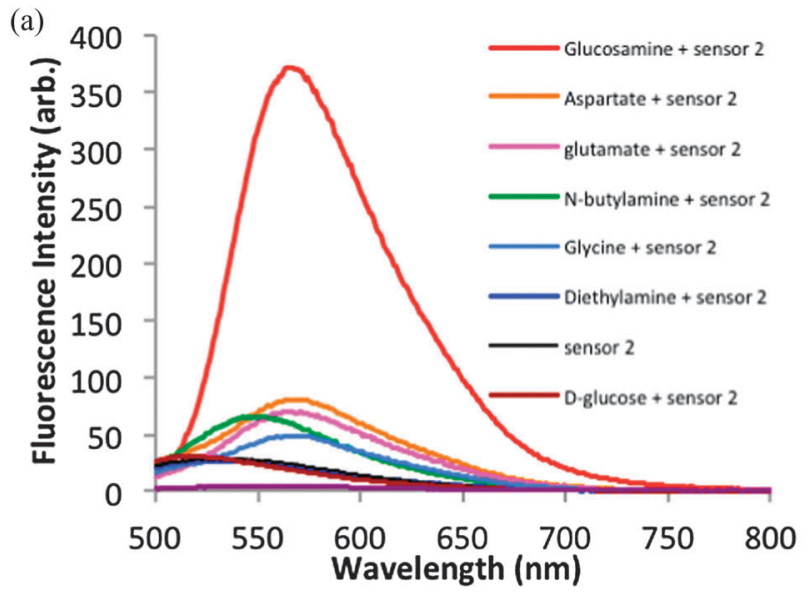

(b)

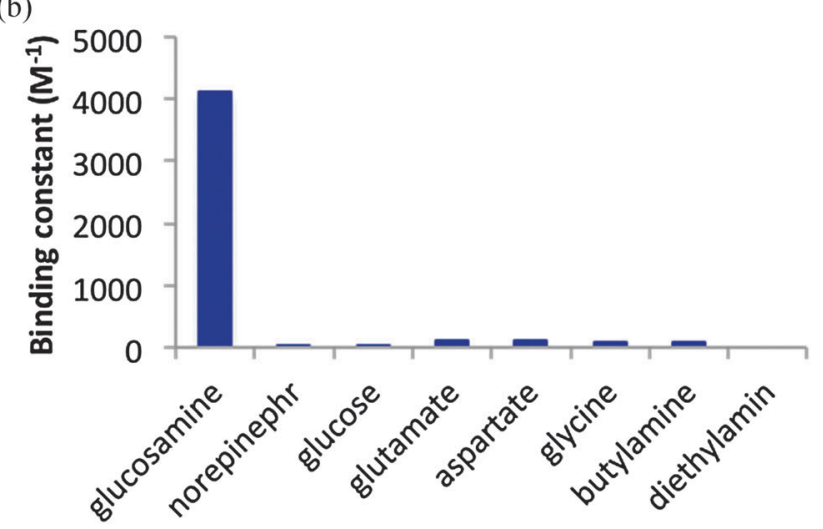

Fig. 2 (a) Fluorescence response of sensor $2\left(10^{-5} \mathrm{M}\right)$ with addition of various analytes at concentration $1 \mathrm{mM},\left(\lambda_{\mathrm{ex}}=488 \mathrm{~nm}\right)$. (b) Binding constants of sensor $\mathbf{2}$ with various analytes.

response to glucosamine than any other analyte. Interestingly, the emission behaviour of this sensor is quite different than other sensors in this series. For sensors such as 1, the emission band stays constant at about $520 \mathrm{~nm}$ upon binding analytes, however it is clear from Fig. 2a that the emission band of sensor 2 shifts almost $50 \mathrm{~nm}$ upon binding glucosamine. This shift gives sensor 2 a Stokes shift of $83 \mathrm{~nm}$ in the bound state. Such large Stokes shifts are helpful for overcoming background fluorescence. This shift in emission upon binding results from the binding geometry that increases the $\pi$-overlap of the aromatic substituent with the fluorophore, leading to higher wavelengths of both excitation and emission. ${ }^{36}$ Taken together, these results indicate that sensor 2 is a very selective sensor for glucosamine both in terms of fluorescent response and binding constant as graphically illustrated in Fig. 2 b.

In conclusion, a new turn-on fluorescent sensor was developed that shows excellent affinity and selectivity to glucosamine over various amines and diol-containing analytes. The suitable geometrical arrangement of multiple functional groups within the sensor produces an ideal binding cavity for glucosamine under physiological conditions of salt and $\mathrm{pH}$. This probe will greatly benefit on-going research on the pharmaceutical effects of glucosamine. In addition, this observed fluorescence responses may inspire research toward highly sensitive and selective fluorescent sensors for other complex biomolecules.

We wish to acknowledge NSF for financial support (CHE1112194) and would like to thank the United States Government, National Academy of Sciences and Vietnam Education Foundation for a graduate fellowship (T.M.T.).

\section{Notes and references}

1 O. Bruyere, K. Pavelka, L. C. Rovita, R. Deroisy, M. Olejarova, J. Gatterova, G. Giacovelli and J. Y. Reginster, Menopause, 2004, 11, 138-143.

2 S. Christgau, Y. Henrotin, L. B. Tanko, L. C. Rovati, J. Collette, O. Bruyere, R. Deroisy and J. Y. Reginster, Clin. Exp. Rheumatol., 2004, 22, 36-42.

3 H. Gray, P. Hucheson and R. Slacin, J. Allergy Clin. Immunol., 2004, 114, 459-460.

4 J. Erickson and T. Messer, J. Hand. Surg. Am., 2013, 38, 1638-1640.

5 C. T. Vangsness, W. Spiker and J. Erickson, Arthroscopy, 2009, 25, 86-94.

6 J. B. Houpt, R. MacMillan, C. Wein and S. D. Paget-Dellio, J. Rheumatol., 1999, 26, 2423-2430; J. Y. Reginster, A. Neuprez, M. P. Lecart and N. Sarlet, J. Rheumatol., 2012, 32, 2959-2967.

7 M. J. Pouwels, J. Jacobs, P. Span, J. Lutterman, P. Smits and C. Tack, J. Clin. Endocrinol. Metab., 2001, 86, 2099-2103. 
8 F. Richy, O. Bruyere, O. Ethgen, M. Cucherat, Y. Herotin and J. Y. Reginster, Arch. Intern. Med., 2004, 163, 1514-1522.

9 T. E. Toweed, L. Maxwell and T. P. Anastassiades, Cochrane Database Syst. Rev., 2005, 2, CD002946.

10 S. Wandel, P. Juni, B. Tendal, E. Nuesch, P. M. Villiger, N. J. Welton, S. Reichenbach and S. Trelle, BMJ., 2010, 314, c4675.

11 A. D. Sawitzke, H. Shi, M. F. Finco, D. D. Dunlop, C. O. Bingham, C. L. Harris, N. G. Singer, J. D. Bradley, D. Silver, C. G. Jackson, N. E. Lane, C. V. Oddis, F. Wolfe, J. Lisse, D. E. Furst, D. J. Reda, R. W. Moskowwits, H. J. Williams and D. O. Clegg, Arthritis Rheum., 2008, 58, 3183-3191.

12 J. H. Quastel and A. Cantero, Nature, 1953, 171, 252-254; B. Q. Liu, X. Meng, C. Li, Y. Y. Gao, N. Li, X. F. Niu, Y. Guan and H. Q. Wang, Exp. Mol. Med., 2011, 43, 487-493.

13 J. Bekesi, Z. Molnar and R. Winzler, Cancer Res., 1969, 29, 353-359.

14 J. Bekesi and R. Winzler, Cancer Res., 1970, 30, 2905-2912.

15 S. Friedman and P. Skehan, Proc. Natl. Acad. Sci. U. S. A., 1980, 77, 1172-1176.

16 E. Krug and A. Zweibaum, Biochem. J., 1984, 217, 701-708.

17 C. Cooper and T. James, J. Chem. Soc., Perkin Trans. 1, 2000, 963-969.

18 R. Cheng, Y. Liu, S. Ou, Y. Pan, S. Zhang, H. Chen, L. Dai and J. Qu, Anal. Chem., 2012, 84, 5641-5644.

19 E. Feuster and T. Glass, J. Am. Chem. Soc., 2003, 125, 16174-16175. 20 K. Secor and T. Glass, Org. Lett., 2004, 6, 3727-3730.

21 J. Klockow and T. Glass, Org. Lett., 2013, 15, 235-237.
22 K. Hettie, X. Liu, K. Gillis and T. Glass, ACS Chem. Neurosci., 2013, 4, 918-923.

23 J. Yan, G. Springsteen, S. Deeter and B. Wang, Tetrahedron, 2004, 60, 11205-11209.

24 C. L. Ni, H. Q. Wang and H. Yan, Youji Huaxue, 2006, 26, 357-359.

25 J. Madhav, B. Kuarm, P. Someshwar, B. Rajitha, Y. Reddy and P. Crooks, J. Chem. Res., 2008, 4, 232-234.

26 N. Kornblum and A. Lurie, J. Am. Chem. Soc., 1959, 81, 2705-2715. 27 T. Ishiyama, M. Murata and N. Miyaura, J. Org. Chem., 1995, 60, 7508-7510.

28 K. Rajanna, F. Solomon and M. Ali, Int. J. Chem. Kinet., 1996, 28, 865-872.

29 J. P. Lorand and J. O. Edwards, J. Org. Chem., 1959, 24, 769-774.

30 T. Kimura, S. Arimori, M. Takeuchi, T. Nagasaki and S. Shinkai, J. Chem. Soc., Perkin Trans. 2, 1995, 1889-1894.

31 J. Yoon and A. W. Czarnink, J. Am. Chem. Soc., 1992, 114, 5874-5875.

32 L. K. Mohler and A. W. Crarnik, J. Am. Chem. Soc., 1993, 115, 2998-2999.

33 T. D. James, K. R. A. S. Sandanayake and S. Shinkai, Nature, 1995, $374,345-347$.

34 J. C. Norrild and H. Eggert, J. Am. Chem. Soc., 1995, 117, 1479-1484.

35 S. J. Friedman and P. Skehan, Proc. Natl. Acad. Sci. U. S. A., 1980, 77, 1172-1176.

36 K. S. Hettie and T. E. Glass, Chem. - Eur. J., 2014, 20, 17488-17499. 